\title{
Analysis of the Influence of Distributed Photovoltaic Power Generation Network on Distribution Network Security and Power Quality
}

\author{
Laiyun Hou \\ Department of Electric Power Engineering, North China Electric Power University, 689 Huadian \\ Road, Baoding, 071003, China \\ houlaiyun123@163.com
}

Keywords: Distributed photovoltaic power generation, the distribution network security.

\begin{abstract}
Distributed photovoltaic power generation is of great importance to optimize energy structure, promote energy conservation and emission reduction, and achieve sustainable economic development. First of all, this paper analyzes the impact of distributed photovoltaic power generation paralleling in network on the distribution network security from two aspects of the operation and maintenance of the distribution network, in order to provide reference for the safe and stable operation of the distribution network. Secondly, this paper analyzes the influence of power quality of distributed photovoltaic power generation paralleling in network, and put forward the measures to solve the problem that is how to reduce the influence of PV power grid connection on voltage quality, and realized the coordinated development of distribution network and distributed photovoltaic power generation.
\end{abstract}

\section{The Overview of Distributed Photovoltaic Power Generation}

Distributed photovoltaic power generation refers specifically to the use of photovoltaic modules, the direct conversion of solar energy into distributed generation systems. It is a new type of comprehensive utilization of power generation and energy with broad prospects for development. It advocates the principle of nearby power generation, nearby power grid, nearby power conversion and nearby use not only to effectively increase the power generation capacity of the same scale of photovoltaic power plants, effectively solve the problem of power loss in boost and long distance transportation. However, due to the small size and large number of photovoltaic power generation systems, the access of a large number of distributed photovoltaic power generation will have a significant impact on the safety and power quality of the power grid.

\section{Influence of Distributed Photovoltaic Power Generation Paralleling in Network on Distribution Network Security}

At present, the low-voltage distribution network is mainly neutral ungrounded (or arc suppression coil grounding) system, using a single-sided power supply type radiation network. Distributed photovoltaic power generation access distribution network, not only makes the distribution network from radiation to multi-power structure, but also change the power flow and short-circuit current size, flow and distribution characteristics.

\subsection{Impact on Operational Safety}

\subsubsection{Relay Protection}

In the case of short-circuit distribution network, distributed photovoltaic power generation network on the distribution network short-circuit current as shown in Fig. 1. 


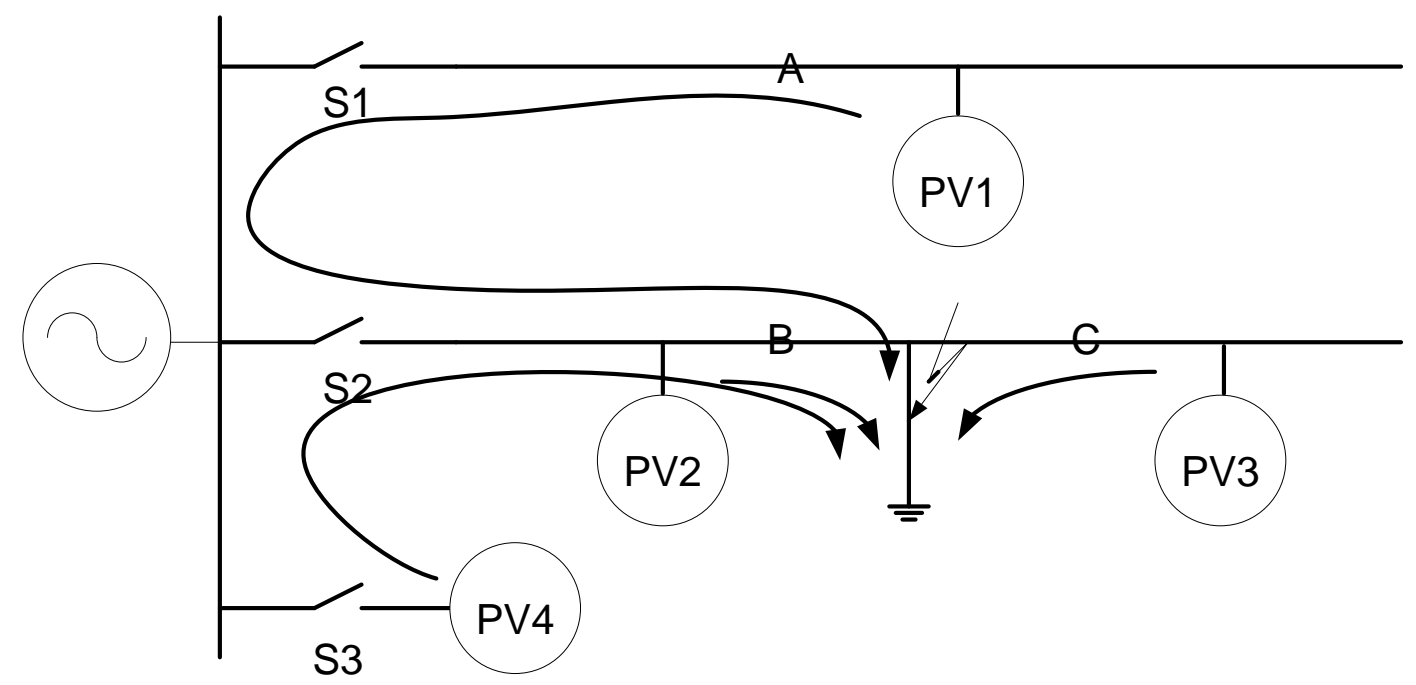

Fig. 1 Influence on Distribution Network Short Circuit Current

When a short circuit occurs between $\mathrm{B}$ and $\mathrm{C}$, the main power supply and each distributed photovoltaic power supply inject a short-circuit current into the short-circuit point, and the short-circuit current increases. Meanwhile, switches S2 and B upstream of the short-circuit point flow short-circuit current from the main power supply, photovoltaic power generation upstream of the present feeder and photovoltaic power generation of other feeders, wherein the short-circuit current from the distributed photovoltaic power causes the feeder voltage of the faulted segment to rise, Making the main power supply short-circuit current and no photovoltaic power generation compared to when compared to reduce.

\subsubsection{Distribution Network Automation}

Distribution Automation (DA) relies on the distribution of short-circuit current in the distribution network for fault location. If one end of an area reports short-circuit current information, and no other end of the area reports short-circuit current information, the fault is in the area. If at least one of the other endpoints also reports the short-circuit current information, the fault Not in the area. However, in the case of distributed photovoltaic access feeder, when a certain area fails, except the main power side end point of the area will flow through the short circuit current supplied by the main grid power, the end of this area connected with the distributed photovoltaic power supply Will also flow through the corresponding distributed photovoltaic power supply for short-circuit current. Therefore, the traditional fault location principle is difficult to apply in the distributed photovoltaic power generation network, which makes it difficult to automate distribution networks.

\subsection{Impact on Maintenance Safety}

The islanding effect means that when the switch QF1 is turned off, the QF2 (or distributed photovoltaic power generation access device) of the common connection point fails to detect the island state and disconnect in time, so that the distributed photovoltaic power generation system still delivers power to the system. When the power grid is out of power due to accident or power outage, if the output of distributed PV power system matches the local load, islanding may occur, resulting in live lines to be repaired (as indicated by the dotted lines in Fig. 2), system equipment and Relevant personnel bring security risks. 


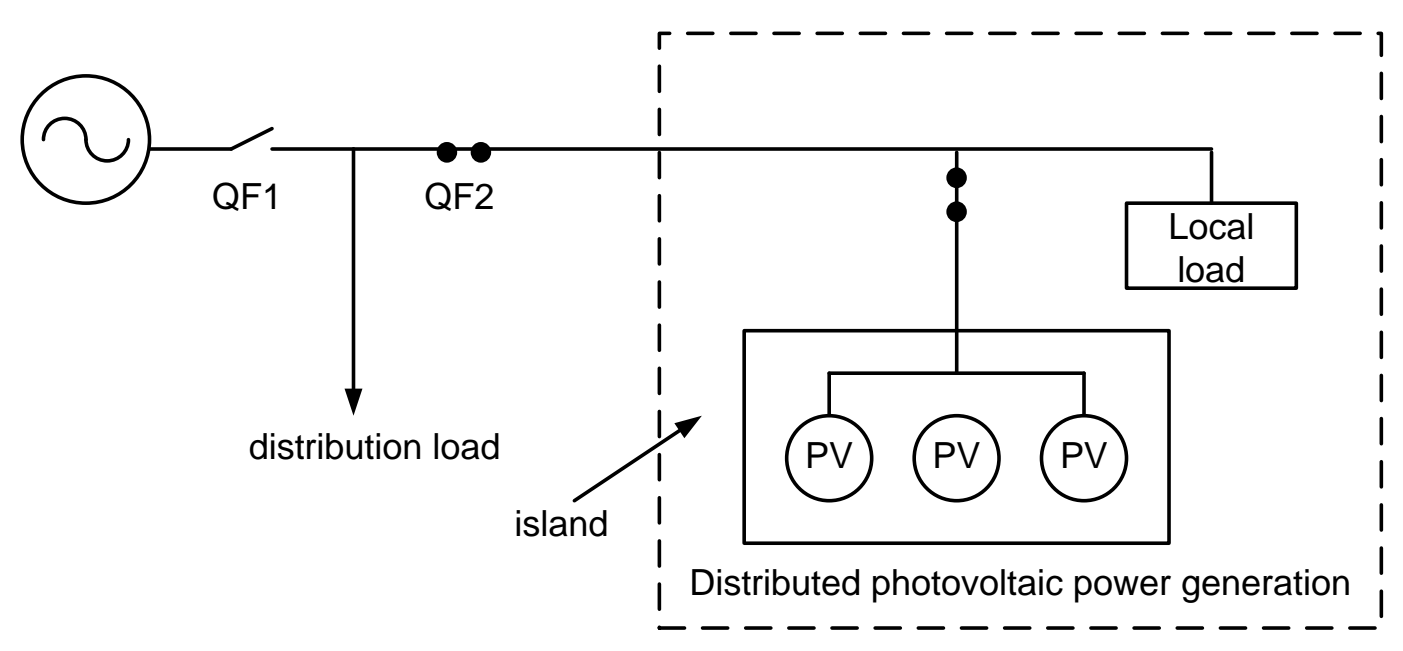

Fig. 2 Photovoltaic system islanding effect diagram

\section{Influence of Distributed Photovoltaic Power Generation Paralleling in Network on Power Quality in Distribution Network}

\subsection{Positive Influence}

(1)Distributed photovoltaic power access distribution network can achieve the balance of energy in the field, to avoid the investment and loss of long-distance transmission. When the associated load in the distribution network is large, the distributed photovoltaic power supply can quickly provide power support and improve the load carrying capacity and system stability of the distribution network.

(2)By reasonably disposing the energy storage device and utilizing the reactive power output capability of the PV grid-connected inverter, the distributed photovoltaic system can be involved in the distribution network voltage, frequency and stability regulation.

(3)The use of photovoltaic grid-connected power generation system and the unified power quality controller (UPQC) structure and control of many similar, the combination of the two can reduce the investment in distribution network equipment to achieve photovoltaic grid-connected power generation, comprehensive management of power quality, power outage Compensation and other functions.

\subsection{Negative Influence}

The access to distributed photovoltaic power supplies has changed the traditional mono-directional radial power supply mode of distribution network. As the output power of distributed PV has randomness, volatility and non-dispatchable characteristics, power quality problems such as voltage fluctuation and flicker, harmonic pollution and voltage overvoltage easily lead to economic losses to users of distribution network, meanwhile, Harm to the safe and stable operation of the photovoltaic system.

\section{Measures to Improve the Voltage Quality of Distribution Network}

Reduce the impact of PV grid on the distribution network voltage to improve the distribution network voltage measures are mainly divided into two categories, one is from the photovoltaic grid system itself to solve, usually by changing the power electronics control strategy to let Photovoltaic participation in distribution network voltage regulation; the other is from the grid point of view, the use of existing voltage regulating means or compensation equipment to reduce the impact of photovoltaic on the distribution network voltage.

\subsection{Improve Photovoltaic Grid System}

Distributed photovoltaic grid on the grid adversely affect the root cause lies in its uncontrollable power output, so to solve the problem of distribution network voltage is to control the photovoltaic power output. 
There are two ways to control the output power of photovoltaic power: one is to change the output power of photovoltaic cells by adjusting the operating point of the photovoltaic panels; the other is to change the output power of the photovoltaic device by adjusting the output power of the energy storage device without changing the working state of the photovoltaic cells. System output. The PV cell array usually works near the maximum power point and reduces the PV output by moving the working point toward the voltage of the open circuit of the solar panel. However, this solution deviates the photovoltaic cell from the maximum power operating point and reduces the photoelectric conversion efficiency of the photovoltaic cell, More energy is consumed in the form of thermal energy in the panel, reducing the life of the panel. In addition, this solution can only reduce the PV output based on the maximum PV power. When the required power is higher than the maximum PV power, the solution fails. With the development of distributed energy storage technologies and the reduction of energy storage devices, the deployment of energy storage devices has become the development trend of distributed photovoltaic systems.

\subsection{Improve Voltage Quality From Grid Perspective}

(1)For the over-voltage problem, the most direct solution is to increase the wire radius, reducing the line impedance, but this is also the least economical solution.

(2)The voltage fluctuation caused by distributed photovoltaic power supply access can be adjusted by changing the tap of the on-load tap-changer. However, this solution cannot effectively deal with the situation that the voltage at the end of the distribution network is over-limited and the tap of the on-load tap changer may be adjusted frequently Will shorten the life of the transformer, and most of the current low voltage distribution network is not equipped with on-load tap-changer.

\section{Summary}

Distributed photovoltaic power generation and the grid, the operation of the distribution network security, overhauling security and power quality and so have brought a certain impact. In the aspect of distribution network safety, it is suggested to improve the maintenance management rules and strengthen the detection of functions such as anti-islanding protection, voltage loss tripping, check closing with voltage and so on for distributed grid-connected photovoltaic power supply, adopt the linkage mode, install negative control device and In line switch PT; In the distribution network power quality, it is recommended to take measures from two aspects of photovoltaic grid system and power grid, so as to improve the power quality more effectively.

\section{References}

[1]. Lijun Chen. Analysis of the Impact of Distributed Photovoltaic Power Generation Network on Distribution Network Security. Power safety technology.Vol.16(2014)No.8,p.13-17.

[2]. Xinglong Wu: Impacts of Grid-connected Photovoltaic Generation on Distribution System(master, Hefei University of Technology,China,2013).p. 16

[3]. Duan Jinadong, Yang Xuying, Yang Wenyu. Study on power flow calculation and voltage profile in distribution system with distributed generation [C]. Asia-Pacific Power and Energy Engineering Conference, 2009

[4]. S. Wakao, H. Takano, N. Nakada and T. Motegi, "Small-scale distributed PV power generation system of networked composition," 3rd World Conference onPhotovoltaic Energy Conversion, 2003. Proceedings of, Osaka, Japan, 2003, pp. 2298-2301 Vol.3.

[5]. Qingran Li: Research on Influence of Distributed Photovoltaic Power Generation System for Power Quality in Distribution Network(master, North China Electric Power University,China,2016).p. 5 